\title{
Are Anti-Interferon Antibodies the Cause of Failure in Chronic HCV Hepatitis Treatment?
}

Antonio Alci Barone, Rose Aparecida Borges Tosta, Fátima Mitiko Tengan, José Humberto Caetano Marins, Norma de Paula Cavalheiro and Bruno Andrade Cardi
Department of Infectious and Parasitic Diseases, Medical School, University of São Paulo, São Paulo, SP, Brazil

A follow-up study was made of 94 chronic hepatitis $\mathbf{C}$ patients at a hepatitis clinic in Brazil, after interferon alpha (IFN- $\alpha$ ) therapy, to determine the influence of anti-interferon antibodies on treatment outcome. Patients diagnosed as having chronic hepatitis $\mathrm{C}$, confirmed by PCR (HCV RNA) and liver biopsy, were treated with interferon alpha $2 \mathrm{a}$ or $2 \mathrm{~b}$ for at least six months, and were followed up for 24 weeks after termination of treatment in order to assess biochemical, virological and clinical pathology responses. Only $6 \%$ of the 94 patients developed anti-IFN antibodies, 70\% presented a biochemical response and $23 \%$ maintained a sustained virological response. Clinical evaluation revealed that in only 2 patients was there progression of fibrosis; the necro-inflammatory score indicated that $72 \%$ maintained the same activity, $12 \%$ had worsening necro-inflammatory activity, and the remaining $16 \%$ had decreased activity. There was no significant correlation of demographic and laboratory variables with levels of anti-interferon antibodies. Similarly, biochemical and virological responses were not influenced by anti-interferon antibodies. Multivariate analysis by logistic regression revealed that clinical pathological parameters, staging and necro-inflammatory activity did not influence the response to the virus.

Key Words: Interferon- $\alpha$, antibodies, chronic HCV, treatment.

Until recently, interferon alpha (IFN- $\alpha$ ) was the only drug commercially available to treat chronic hepatitis caused by hepatitis $\mathrm{C}$ virus [1]. Three types of interferon alpha, known as 2a, $2 \mathrm{~b}$ and $\mathrm{n} 1$, have been used in Brazil. Among these, $2 \mathrm{a}$ and $2 \mathrm{~b}$ are recombinant forms, whereas IFN- $\alpha \mathrm{n} 1$, called lymphoblastoid, is natural and is produced in lymphoblast cultures. The results obtained with any of them are similar, but are far from what we would consider satisfactory. In various

Received on 10 November 2003; revised 12 February 2004. Address for correspondence: Dr.Antonio Alci Barone. Av. Dr. Enéas de Carvalho Aguiar, 500, sala 12, São Paulo, SP, Zip code: 05403-000, Brazil.

Study conducted at LIM 47 - Laboratory of Medical Investigations in Hepatitis and LIM 52 - Laboratory of Medical Investigations in Virology, Medical School. Department of Infectious and Parasitic Diseases, Medical School, University of São Paulo.

The Brazilian Journal of Infectious Diseases 2004;8(1):10-17 (C) 2004 by The Brazilian Journal of Infectious Diseases and Contexto Publishing. All rights reserved. studies conducted all over the world, about $40 \%$ to $50 \%$ transient responses have been reported, but only $15 \%$ to $20 \%$ of the patients had a sustained response, which was maintained after discontinuation of therapy. One of the factors that has been responsible for the low cure rates is the development of anti-IFN antibodies by the patients after a period of drug use. These antibodies cancel the antiviral and immunomodulating effects of the drug, making it innocuous against HCV. In some cases, IFN- $\alpha \mathrm{n} 1$ has been indicated when patients developed antibodies against IFN types $2 \mathrm{a}$ and $2 \mathrm{~b}$ [1].

In the 90's, ribavarin, an antiviral known for a long time for its in vitro action against some groups of viruses, was released for the treatment of chronic hepatitis $\mathrm{C}$, associated with IFN- $\alpha$. This association increases sustained rates of treatment success to $42 \%$ [1]. Recently, a slow release form of IFN - pegilated IFN, was approved for once weekly dose use, increasing the efficiency of association with ribavarin to $50 \%$ sustained response. It is important to bear in 
mind that both IFN- $\alpha$ and ribavarin are non-specific drugs for $\mathrm{HCV}$, and it is unlikely that we will obtain better results with such drugs $[7,8]$.

Our objectives were:

1. To investigate the development of anti-IFN antibodies in patients with $\mathrm{HCV}$ chronic hepatitis treated with one of the available IFN- $\alpha$ forms.

2. To analyze the influence of these antibodies on treatment outcomes.

\section{Material and Methods}

We examined the sera of 94 patients treated for $\mathrm{HCV}$ chronic hepatitis followed up at the Hepatitis Ambulatory Clinic, Clinical Division of Infectious and Parasitic Diseases, Hospital das Clinicas, Medical School, University of São Paulo, who had been treated with one of the IFN- $\alpha$ preparations, in monotherapy, for at least six consecutive months. Indications for treatment, and inclusion and exclusion criteria for the protocol, were those classically described by most authors and previously reported by us [2]. The dose normally used in our ambulatory is three million units, administered subcutaneously, three times a week, during six months to one year. We used two serum samples, collected before and six months after onset of treatment. The samples were maintained at $-20^{\circ} \mathrm{C}$. The project was approved by the Research Ethics Committee of the institution. We investigated interferon alpha types $2 \mathrm{a}, 2 \mathrm{~b}$ and $n 1$ using ELISA (Enzyme-linked immunosorbent assay), standardized as described below.

\section{Immunization of $C B A / J$ mice with recombinant $I F N-\alpha$}

CBA/J mice, used for the collection of hyperimmune anti-IFN- $\alpha$ recombinant serum, were obtained from the rearing facility of the Institute of Tropical Medicine of São Paulo, and kept in cages with sterilized absorbent material, receiving water and food $\mathrm{ad}$ libitum. Male mice $(\mathrm{n}=10)$ weighing between 25 and 30 grams were inoculated with recombinant IFN, using the classical immunization protocol described by Harlow \& Lane [3], with some minor modifications.

The first inoculum consisted of $150,000 \mathrm{U}$ of recombinant IFN- $\alpha$, in an emulsion of complete Freund's adjuvant, in a total volume of $100 \mu \mathrm{L}$, for subcutaneous administration on the backs of the animals in two separate and subsequent inoculua (50 $\mu \mathrm{L} / \mathrm{each})$.

Fifteen days later, a second inoculum was administered at the same concentration, but in an emulsion of incomplete Freund's adjuvant. Seven days later, the animals were bled through the retro-orbital plexus, from where we collected about $500 \mu \mathrm{L}$ of blood. After separating the serum, we evaluated the humoral response ( $\mathrm{IgG}$ ) by ELISA, using challenges with recombinant IFN- $\alpha$.

Seven days after bleeding, new inoculum and bleedings were made, under the same conditions and with the same methodology. After seven more days, depending on the individual humoral responses of the animals, they received a booster dose, under the same conditions as the second inoculum, followed by final bleeding after four days, when the animals presented a satisfactory humoral response.

Final bleeding was made of previously anesthetized animals that were exsanguinated, and the blood was used as a source of hyper-immune serum, after maintaining total blood for 30 minutes in the incubator at $37^{\circ} \mathrm{C}$, followed by 30 minutes at $4^{\circ} \mathrm{C}$. Next, the material was centrifuged (1,500 rpm, 15 minutes) and the supernatant (serum) was collected and immediately inactivated at $56^{\circ} \mathrm{C}$ for 30 minutes. Finally, the serum was divided into $100 \mu \mathrm{L}$ aliquots, which were maintained at $-20^{\circ} \mathrm{C}$, till they were used.

The manipulation of the animals during the various stages of the assay was in compliance with the laboratory animal care regulations (NIH publ. No. 8623 , reviewed in 1985) and the ethical principles of experimentation in animals (COBEA - Brazilian College of Animal Experimentation).

\section{ELISA reaction for Anti-IFN antibody detection}

$\underline{\text { Standardization }}$

Different dilutions of antigen (IFN), serum (from IFN 
sensitized mice) and conjugate were used, as described below; the selected dilutions are marked in bold:

Ag: $1 / 20 ; \mathbf{1 / 8 0} ; 1 / 320 ; 1 / 1,280$

Serum: 1/20; 1/100; 1/400; 1/600; 1/3,200

Conjugate: $1 / 500 ; \mathbf{1} / \mathbf{1 , 0 0 0} ; 1 / 2,000$

ELISA plates (Polysorp - NUNC immunoplate) were sensitized, solid phase, with 450,000IU of a summation solution of the following types of IFN- $\alpha$ : IFN$\alpha 2 \mathrm{a}$ (Roferon-A, Roche), IFN- $\alpha 2 \mathrm{~b}$ (Biosintética) and IFN- $\alpha 2 b$ (Intron*A, Schering-Plough) and were incubated for two hours at room temperature.

Next, we rinsed the samples with $0.1 \%$ PBS-Tween to eliminate particles that were not fixed to the plate, made the block to fill the remaining spaces among the antigens $(200 \mu \mathrm{L}$ of skim milk at $5 \%$ with PBS/Tween) and incubated at $37^{\circ} \mathrm{C}$ for 1 hour.

After discarding the excess milk, the serum samples, diluted $1 / 20$, were added and maintained at $37^{\circ} \mathrm{C}$ for 1 hour. Non-fixed antibodies were eliminated by rinsing and the conjugate was labeled with peroxidase (Goat anti-Human $\operatorname{IgG}(\wp)$ Horseradish peroxidase) in 1/1,000 dilution, added and maintained at $37^{\circ} \mathrm{C}$ for 45 minutes. After rinsing, the chromogenic substance (OPD + Perborate Buffer) was added and the plates were maintained at room temperature for 20 minutes in the absence of light. A solution of $0.1 \mathrm{~N}$ sulfuric acid was used to interrupt the reaction.

Absorbance at $492 \mathrm{~nm}$ was measured by spectrophotometry (Titertek Multiskan Plus MK Flow Lab.) and results were expressed in optical density units. We considered positivity when the values exceeded the mean plus three times the standard deviations of 16 negative controls (8 patients with $\mathrm{HCV}$ who had never been treated with IFN and 8 subjects without diagnosis of hepatitis) [4]. (The working volume maintained in the reaction was $50 \mu \mathrm{L}$.)

The response to treatment included biochemical criteria (values of alanine aminotransferase - ALT), virological parameters (presence of HCV RNA by polymerase chain reaction - PCR) and clinical pathology (liver biopsy). We considered three types of response: absent, transient and sustained. Absent response was characterized by no normalization of ALT, no negativation of PCR and no improvement of necro-inflammatory activity in the liver biopsy. As to transient response, the parameters were normal only during treatment and resumed their abnormality once the therapy was interrupted. Sustained response was detected when the results of evaluations were normal up to six months after discontinuation of treatment.

\section{Statistical analysis}

In order to compare the proportion of patients with anti-IFN antibodies with the presence of RNA HCV and otherfactors, we used the chi-square test or the Fischer exact test for small samples. Continuous variables (age, ALT, AST and GGT) and ordered exposure variables (staging of liver tissue and necroinflammatory activity) were categorized, considering the scores as continuous.

In order to estimate the risk of sustained virological infection, associated with the factors under study (ALT, AST, GGT, staging and necro-inflammatory activity of liver fragment and production of anti-IFN antibodies) we calculated the odds ratios (OR) and the $95 \%$ confidence interval $(95 \% \mathrm{CI}$ ) as estimates of relative risk (Breslow \& Day, 1980), considering the presence of RNA HCV as the dependent variable and the selected factors as the independent variables. Odds ratios were adjusted for gender and age (14-30; 31-50; >50 years). We considered alpha $=5 \%$.

We also employed a non-conditional logistic regression analysis (similarity ratio) to analyze the various factors, by using the statistical program SPSS version 10.0 .

\section{Results}

\section{General data}

The age of patients included in the study varied from 14 to 70 years $($ mean $=40.9 ;$ median $=40.5$; mode $=$ 42). Sixty-one of the patients $(64.9 \%)$ were male. Serum levels of ALT (baseline - before treatment) 
varied from 9 to $254($ mean $=54.096 ;$ median $=43.0$; mode $=22$ ); AST (baseline) from 8 to 148 (mean = 34.617 ; median $=28.5$; mode $=13.0$ ).

\section{Biochemical response}

At the end of 6 months after suspension of treatment, 66 of the patients (70\%) maintained ALT serum levels below 1.5 times the upper normal limit.

\section{Histological response}

In the assessment of necro-inflammatory activity during the period, 68 patients (72\%) maintained the same activity; $11(12 \%)$ showed worsening of the necro-inflammatory activity and 15 patients (16\%) presented reduction of activity. When liver staging was examined, 92 patients maintained the same staging and two showed worsening.

\section{Anti-interferon antibody}

The distribution of patients according to levels of anti-interferon antibody and the relation to other factors is shown in Table 1.

\section{Virological response}

The distribution of patients according to virological response (six months after interruption of treatment), and the other factors, is shown in Table 2.

\section{Logistic regression}

The variables necro-inflammatory activity of liver fragments, staging of liver fragment and fibrosis, and presence of anti-interferon antibodies, were tested to build the logistic regression model. The final model consisted of the variables staging and necroinflammatory activity of liver fragments (Table 3 ).

\section{Discussion}

Since the study by Vallbrach [9], who demonstrated anti-IFN antibodies for the first time more than two decades ago, many scientists have become concerned about this topic, but no one has found a definite response about their influence on the therapeutic response. As is known, anti-IFN antibodies can occur naturally in subjects who have never received the drug, probably owing to the endogenous production of powerful antigenic stimuli [10]. In the many studies that followed since Eisenberg in 1986 [16], it has been found that these antibodies can be present in variable percentages after the use of IFN (2.4 to 63\%), but most reports have shown no differences in therapeutic response. The studies of neoplasm treatments generally showed higher rates of anti-IFN antibody production than the studies on hepatitis treatment or treatment of other viral diseases, and some showed an even greater influence of these antibodies on the final outcome. In addition, the fact that they arehighly specific antibodies against specific epitopes of IFN molecules, helps explain the changes in IFN when they are present [11,12].

In the case of hepatitis $C$ treatment, research studies with anti-IFN antibodies were more numerous and consistent in the 90's. Studies were made to distinguish two types of antibodies, the ligant and the neutralizer, but ended up showing that they were present in similar proportions in patients that received the continuous versus intermittent therapeutic schemes [5]. Since 1996, the response to chronic hepatitis $\mathrm{C}$ began to be monitored by molecular biology techniques, such as PCR. Of five studies [13,14,17-19] that have assessed virological responses, only one of [14] showed correlation between breakthrough and presence of anti-IFN antibody.

In our study, in addition to biochemical and virological responses, we conducted a histological analysis of liver biopsies performed before and up to six months after treatment, to evaluate the modifications in staging, measured by fibrosis, and in necro-inflammatory activity in the portal space and periportal and lobular regions.

We observed that a reduced number of patients developed anti-IFN antibodies during treatment (6\%). Of the 94 patients followed up for six months after treatment, $71 \%$ presented a biochemical response, $72 \%$ maintained unaffected necro-inflammatory responses and 96\% did not experience progression in staging. Twentytwo of the 94 patients showed sustained virological 
Table 1. Distribution of patients with HCV infection according to production of anti-interferon (IFN) antibodies during treatment with IFN- $\alpha$ in relation to baseline characteristics of the patients (demographic and laboratory data).

\begin{tabular}{|c|c|c|c|}
\hline \multirow[t]{2}{*}{ Patients' characteristics } & \multicolumn{2}{|c|}{ Anti-IFN antibody } & \multirow[t]{2}{*}{$\mathbf{p}$} \\
\hline & Positive & Negative & \\
\hline \multicolumn{4}{|l|}{ Gender } \\
\hline male & 4 & 57 & 0.65 \\
\hline female & 2 & 31 & \\
\hline \multicolumn{4}{|l|}{ Age (years) } \\
\hline Up to 30 & 1 & 8 & 0.40 \\
\hline $31-50$ & 3 & 66 & \\
\hline$>60$ & 2 & 14 & \\
\hline \multicolumn{4}{|l|}{ ALT1 } \\
\hline Up to LSN & 2 & 40 & 0.84 \\
\hline $1 \mathrm{LSN}-1.5 \mathrm{LSN}$ & 3 & 35 & \\
\hline$>1.5 \mathrm{LSN}$ & 1 & 13 & \\
\hline \multicolumn{4}{|l|}{$\underline{\mathrm{AST} 1}$} \\
\hline Up to LSN & 3 & 67 & 0.27 \\
\hline 1LSN-1.5LSN & 2 & 17 & \\
\hline$>1.5 \mathrm{LSN}$ & 1 & 4 & \\
\hline \multicolumn{4}{|l|}{$\underline{\text { GGT1 }}$} \\
\hline Up to $1.5 \mathrm{LSN}$ & 4 & 62 & 0.58 \\
\hline$>1.5 \mathrm{LSN}$ & 2 & 26 & \\
\hline \multicolumn{4}{|l|}{$\underline{\text { Necro-inflammatory activity }}$} \\
\hline 1to 4 & 5 & 39 & 0.08 \\
\hline$>4$ & 1 & 49 & \\
\hline \multicolumn{4}{|l|}{ Staging } \\
\hline Up to 2 & 2 & 46 & 0.32 \\
\hline $2-4$ & 4 & 42 & \\
\hline
\end{tabular}

LSN: Upper normal limit. 
Table 2. Distribution of patients with HCV infection according to presence of RNA HCV six months after treatment, in relation to baseline characteristics of the patients (demographic and laboratory data).

\begin{tabular}{|c|c|c|c|}
\hline \multirow[t]{2}{*}{ Patients' characteristics } & \multicolumn{2}{|c|}{ RNA HCV } & \multirow[t]{2}{*}{$\mathbf{p}$} \\
\hline & Positive & $\overline{\text { Negative }}$ & \\
\hline \multicolumn{4}{|l|}{ Gender } \\
\hline male & 45 & 16 & 0.53 \\
\hline female & 27 & 6 & \\
\hline \multicolumn{4}{|l|}{ Age (years) } \\
\hline Up to 30 & 7 & 2 & 0.98 \\
\hline $31-50$ & 53 & 16 & \\
\hline$>60$ & 12 & 4 & \\
\hline \multicolumn{4}{|l|}{ ALT1 } \\
\hline Up to LSN & 32 & 10 & 0.11 \\
\hline 1LSN-1.5LSN & 27 & 11 & \\
\hline$>1.5 \mathrm{LSN}$ & 13 & 1 & \\
\hline \multicolumn{4}{|l|}{ AST1 } \\
\hline$\overline{\mathrm{Up}}$ to $\mathrm{LSN}$ & 50 & 20 & 0.25 \\
\hline $1 \mathrm{LSN}-1.5 \mathrm{LSN}$ & 17 & 2 & \\
\hline$>1.5 \mathrm{LSN}$ & 5 & 0 & \\
\hline \multicolumn{4}{|l|}{ GGT1 } \\
\hline Up to LSN & 36 & 12 & 0.75 \\
\hline $1 \mathrm{LSN}-1.5 \mathrm{LSN}$ & 15 & 3 & \\
\hline$>1.5 \mathrm{LSN}$ & 21 & 7 & \\
\hline \multicolumn{4}{|l|}{ Necro-inflammatory activity } \\
\hline 1 to 4 & 34 & 10 & 0.92 \\
\hline$>4$ & 38 & 12 & \\
\hline \multicolumn{4}{|l|}{ Staging } \\
\hline Up to 2 & 59 & 20 & 0.26 \\
\hline $2-4$ & 2 & 2 & \\
\hline \multicolumn{4}{|l|}{ Anti-IFN antibodies } \\
\hline Positive & 6 & 0 & 0.19 \\
\hline Negative & 66 & 22 & \\
\hline
\end{tabular}

LSN: Upper normal limit. 
Table 3. Distribution of patients with HCV infection according to necro-inflammatory activity and structural staging of liver fragments

\begin{tabular}{lccc}
\hline Risk factor & OR $^{\mathbf{1}}$ & OR $^{2}$ & CI (95\%) \\
\hline Staging & & & \\
\hline $0-2$ & 1.00 & 1.00 & $0.08-2.11$ \\
$\quad 3-4$ & 0.44 & 0.42 & \\
Necro-inflammatory activity & & & \\
$\quad$ Up to 4 & 1.00 & 1.00 & $0.44-3.16$ \\
$\quad>4$ & 1.04 & 1.17 & \\
\hline
\end{tabular}

$\mathrm{OR}^{1}$ : adjusted for gender and age.

$\mathrm{OR}^{2}$ : adjusted for gender, age and variables of Table 1.

responses. There was no correlation between the presence of anti-interferon antibodies and demographic variables and laboratory data of the patients. Similarly, these variables did not influence the virological response 24 weeks after the end of treatment. Multivariate analysis by logistic regression did not show any significant correlation between the clinical pathologic parameters and virological response to treatment.

In conclusion, our analysis of biochemical, virological and clinical pathologic responses did not show any correlation between the presence of anti-interferon antibody and response to treatment.

\section{References}

1. Mchutchinson J. Hepatitis $C$ therapy in treatment-naive patients. Am J Med 1999;107(6B):56-61.

2. Barone A.A., Cavalheiro N.P., Suematsu S. Response in patients with chronic HCV hepatitis to treatment with Interferon-alpha. Baz J Infet Dis 1999;3(3):118-28.

3. Harlow E., Lane D. Antibodies. A Laboratory Manual. Ed. Cold Sprig Harbor Lab, N.Y., 1988.

4. Engvall E., Perlmann P. Enzyme-linked immunosorbent assay (ELISA) quantitative assay of immunoglobulin G. Immunochemistry 1971;8: 871-4.

5. Hoofnagle J.H., di Bisceglie A.M., Shindo M. Antiviral therapy of Hepatitis $\mathrm{C}$ - present and future. J Hepatol 1993;17(3):130-6.
6. Lok A.S., Lai C.L., Leung E.K.Y. Interferon antibodies may negate the antivral effects of recombinant alphainterferon treatment in patients with chronic Hepatitis B virus infection. Hepatology 1990;12:1266-70.

7. Peters M. Mechanisms of action of interferons. Semin Liver Dis 1989;9(4):2359.

8. Tong M.J., Reddy K.R., Lee W,M. Treatment of chronic hepatitis $\mathrm{C}$ with consensus interferon: a multicenter, randomized, controlled trial. Hepatology 1997;26(3):747-54.

9. Vallbracht A., Treuner J., Flehmig B., et al. Interferon neutralizing antibodies in a patient treated with human fibroblast interferon. Nature 1981;289:496-7.

10. Ikeday Y., Toda G., Hashimoto N., et al.Naturally ocurring anti-interferon-alpha2a antibodies in patients with acute viral hepatitis. Clin Exp Immunol 1991;85:80-4.

11. Antonelli G., Currenti M., Turriziani O., Dianzani F. Neutralizing antibodies to interferon-alpha: Relative frequency in patients treated with different interferon preparations. J Infect Dis 1991;163:882-5.

12. Nolte K.-U., Günther G., von Wusson P. Epitops recognized by neutralizing therapy-induced human anti-interferonalpha antibodies are localized within the N-terminal functional domain of recombinant interferon-alpha2. Eur J Immunol 1996;26:2155-9.

13. Hanley J.P., Jarvis L.M., Simmonds P., Ludlam C.A. Development of anti-interferon antibodies and breakthrough hepatitis during treatment for $\mathrm{HCV}$ infection in haemophiliacs. Br J Haematol 1996;94(3-I):551-6.

14. Leroy V., Baud M., de Traversay C., et al. Role of antiinterferon antibodies in breakthrough ocurrence during alpha $2 \mathrm{a}$ and $2 \mathrm{~b}$ therapy in patients with chronic hepatits C. J Hepatol 1998;28:375-81. 
15. Negro F., Baldi M., Mondardinia A., et al. Continuous versus intermittent therapy for chronic hepatitis $C$ with recombinat interferon alpha-2a. Gastroenterology 1994; 107:479-85.

16. Eisenberg M., Rosno S., Garcia G., et al. Preliminary trial of recombinant fibroblast interferon in chronic hepatitis $\mathrm{B}$ virus infecction. Antimicrob Agents Chemother 1986;29(1):122-6.

17. Wembint T., Chunying Z., Baiafang F., et al. Autoantibodies and anti-interferon antibody with chronic viral hepatitis and its clinical significance: a preliminary investigation. Chin Med J 1997;110(10): 769-73.

18. Hou C., Chuang W.L., Yu M.L., et al. Incidence and associated factors of neutralizing anti-interferon antibodies among chronic hepatitis $\mathrm{C}$ patients treated with interferon in Taiwan. Scand J Gastroenterol 2000;20:1288-93.

19. Stancek D., Fuchsberger N., Oitman M., et al. Significance of anti-interferon-alpha2 and sICAM-1 activities in the sera of viral hepatitis $B$ and $C$ patients treated with human recombinant interferon-alpha2. [Abstract] Acta Virol 2001;45(5-6): 287-92. 